\title{
Personal characteristics \\ of professional self-realization \\ of a designer in the digital age
}

\section{A. A. Kyuregyan ${ }^{1}$}

${ }^{1}$ Leonov Technological University, 42 Gagarina str., Korolev, Moscow region 141074, Russian Federation

DOI: $10.18255 / 1996-5648-2021-2-290-298$

Research article

Full text in Russian

This article describes the specifics of the professional activity of a designer in the digital age. The analysis of personal features of professional self-realization of designers on the basis of expert assessment for the purpose of their definition and subsequent formation at the stage of training of the profession is carried out. The provisions formulated in the article can be used in a comprehensive study of the personality characteristics of the designer as a subject of professional activity.

Keywords: professional self-realization; personal characteristics; professional activity of a designer; psychology; communicative competence

\section{INFORMATION ABOUT AUTHORS}

\begin{tabular}{l|l} 
Kyuregyan, Anastasia A. & $\begin{array}{l}\text { E-mail: An.Kyureg@gmail.com } \\
\text { PhD student }\end{array}$
\end{tabular} 


\title{
Личностные особенности профессиональной самореализации дизайнера в цифровую эпоху
}

\author{
А. А. Кюрегян ${ }^{1}$
}

${ }^{1}$ Технологический университет им. А. А. Леонова, ул. Гагарина, 42, Королев, Московская область, 141074, Российская Федерация

DOI: $10.18255 / 1996-5648-2021-2-290-298$

УДК 159.9.07

Научная статья

Полный текст на русском языке

В статье описывается специфика профессиональной деятельности дизайнера в цифровую эпоху. Проведен анализ личностных особенностей профессиональной самореализации дизайнеров на основе экспертного оценивания и последующего фрормирования на этапе обучения профессии. Положения, сорормулированные в статье, могут быть использованы при комплексном изучении особенностей личности дизайнера как субъекта профессиональной деятельности.

Ключевые слова: профессиональная самореализация; личностные особенности; дизайнер; психология; коммуникативная компетентность

\section{ИНФОРМАЦИЯ ОБ АВТОРАХ}

Кюрегян, Анастасия Алексеевна $\mid$ E-mail: An.Kyureg@gmail.com

Аспирант

Введение. Проблема развития творческой личности в наши дни является особенно острой. Доля креативной индустрии растёт, занимая солидную часть экономики Москвы, являясь ее движущей силой. По сообщению правительства от 10.04.2019, с точки зрения динамики бизнеса креативный сектор Москвы занимает первое место в мире. В нем задействовано от 2 до 8 \% общей численности экономически активного населения [1]. В большинстве своём это люди творческих профессий. Парадоксально, но показатель креативности населения, обусловленный цифровой эпохой, резко снижается. Сейчас мы можем говорить о кризисе творческих идей, который все чаще упоминается учёными, исследующими креативность по всему миру. Легкая доступность информации, обилие цифрового контента, которые поначалу стимулировали креативность, сейчас становятся барьером потока новых идей [2].

Одним из ведущих направлений креативной индустрии является дизайн. В группе этих профессий (дизайнер одежды, интерьера, художник

(C) Кюрегян А. А., 2021

Статья открытого доступа под лицензией CC BY (https://creativecommons.org/licenses/by/4.0/) 
Кюрегян А. A.

по костюму, стилист и т. д.) особенно высока степень взаимного проникновения личностного и профессионального. Сама специфика профрессиональной деятельности заключается в определенном противоречии: сохранение индивидуальности, "личного почерка" исполнителя, с одной стороны, достижения дизайнера - с другой обусловливаются отношением, оценкой публики, клиентов и профессионального сообщества. Нельзя забывать и про размытость, изменчивость критериев профессиональной успешности, их зависимость от внешних подтверждений успеха, не всегда предсказуемых [3].

В связи с этим видится перспективным анализ личностных особенностей профессиональной самореализации дизайнеров на основе экспертного оценивания с целью их определения и последующего фрормирования на этапе обучения профессии. Объектом данного исследования является личность профрессионала в сорере «дизайн». Предмет наших исследовательских интересов - личностные особенности профессиональной самореализации дизайнеров. В рамках данного исследования мы ставим перед собой следующие задачи:

- описать специфику профессиональной деятельности дизайнера в цифровую эпоху;

- выявить важнейшие личностные качества дизайнера в соответствии с актуальными требованиями профессии на основе контент-анализа экспертной группы.

В исследовании мы опираемся на современные подходы к изучению саморазвития и профессиональной самореализации личности, разрабатываемые такими учеными, как К. А. Абульханова-Славская, Б. Г. Ананьев, Л. И. Анцыферова, К. Гольштейн, И. В. Костакова, С. И. Кудинов, А. И. Купнов и др. Возрастающее внимание и интерес к данной проблеме позволили накопить большой массив теоретических и эмпирических знаний в области профессиональной самореализации личности. Вместе с тем остается множество нерешенных вопросов и неисследованных задач в системе профрессиональной самореализации дизайнеров.

Основная часть. Современная цифровая эпоха накладывает определенные требования как к навыкам дизайнера, которыми он должен владеть, так и к личностным чертам, которыми специалист, желающий реализоваться в профессии, должен обладать. В XXI веке произошел резкий сдвиг в сторону цифровой экономики, который стимулировал развитие визуальных цифровых технологий. На первый план выходят эксперименты с виртуальной и дополненной реальностью, им пророчат большое будущее как новым маркетинговым каналам [4]. Рост потребления, высокая скорость смены коллекций, финансовая нестабильность идут рядом с профрессиональными и личностными сложностями дизайнеров: профессиональным выгоранием, проблемой адаптации к цифровизации отрасли, вынужденной текучестью кадров и сменой работы. Сегодня сферу моды и дизайна 
Личностные особенности профессиональной самореализации...

нельзя назвать устойчивой ни с точки зрения экономики, ни с точки зрения самих профессионалов-дизайнеров, подверженных постоянному давлению и изменениям внутри среды. В век интернета, социальных сетей, онлайн-показов и магазинов «в сети» проблема оценки творческого продукта становится особенно острой. Теперь за деятельностью дизайнера следит весь мир. Сокращение дистанции в коммуникации «творец-зритель», открытые, доступные средства для выражения мнения о творениях дизайнера могут влиять - не всегда положительно - на психологическую устойчивость специалиста.

Фундаментальная проблема для устоявшихся модных брендов заключается в том, что они все больше отстают от ожиданий потребителей. Теперь дизайнеру недостаточно обладать творческим потенциалом и грамотно владеть техническими навыками. В первую очередь важно быть в достаточной степени осведомленным о тенденциях изменений в обществе, которое является и заказчиком, и потребителем дизайна. В действительности, роль потребителя изменилась - от пассивного наблюдения к активному доминированию [5]. Информированные, избирательные и социально ответственные современные покупатели заботятся о том, как они выглядят на публике и в социальных сетях, а также о том, как воспринимаются окружением те товары, которые они приобретают и которыми владеют. По сообщению руководителя проектов модной индустрии компании «Яндекс», подавляющее большинство использует цифровые каналы до, во время или после совершения покупок [6].

Устанавливаются новые стандарты постпродажного обслуживания. Речь идет о переходе от бренда «продукта» к тому, чтобы стать брендом, который фрормирует контекст и предложение, ориентируясь на потребителя, на его поведение и предпочтения в интернет-сетях. Мода стала меняться все более стремительно, и перед дизайнерами сейчас стоит этот вызов. Социальный опрос Агентства «РБК Исследование рынков» 2020 года, включающий в себя более 4000 респондентов, показал, что онлайн-шопинг является глобальным трендом на рынке fashion-товаров в России. Доля онлайн в структуре рынка в 2020 г. более, чем удвоилась. В 2019 г. показатель был равен $12 \%$, а в 2020 г. - $27 \%$ [7]. На российском рынке продолжает доминировать «smart shopping» как модель потребления. Это прежде всего связано с падением доходов населения: сведение к минимуму доли спонтанных покупок. Люди реже стали покупать предметы гардероба просто потому, что вещь понравилась, клиенты модных марок стали делать это осознанно. Соответственно, конкуренция между брендами возрастает.

По заявлению РБК, II квартал 2020 г. отметился рекордным обвалом продаж fashion-товаров (-37\%). Это явилось следствием закрытия розничных магазинов в период карантина и некоторое время уже после его окончания. Падение является рекордным - больше, чем в кризисный 2015 г. или 2008 г. [6] Однако некоторые дизайнеры, сумевшие грамотно встроить- 
ся в новую повестку дня и внедрившие определенные изменения в деятельность собственного бренда, сообщили о стабильном доходе, несмотря на пандемию короновируса Covid-19. Среагировать на нее помогли не только профессиональные навыки, но и личностные особенности. Основной причиной, позволившей им успешно продолжать профессиональную деятельность без серьезных экономических потерь, как отметили дизайнеры А. Артемов, О. Малюга, Н. Брянцева, стала «интуиция». При этом сами дизайнеры не дают точного определения понятия интуиции и не могут объяснить, какие психологические и личностные характеристики позволили им преодолеть кризис локдауна. Такие прогностические личностные способности недостаточно изучены, что подтверждает актуальность нашего исследования.

Для выявления личностных качеств и характеристик было необходимо исследовать экспертное мнение. В связи с этим мы провели исследование методом контент-анализа видео- и аудиоинтервью, а также онлайн-выступлений профрессионалов-дизайнеров на фроруме модной индустрии BeinOpen в 2020 г.

На первом этапе исследования нами были отобраны респонденты. Критерием включения испытуемого в выборку были следующие условия: респондент должен был работать в индустрии не менее 5 лет, являться главным представителем бренда, коммерчески успешного. Таким образом, в исследовании приняли участие 33 эксперта. Из них 24 человека - дизайнеры одежды, обуви, тканей, украшений и интерьера, 4 - стилисты, 5 - работники смежных областей (1 - историк моды, 1 - креативный директор глянцевого медиа, 3 - креативные продюсеры). В числе опрошенных - 18 женщин и 15 мужчин, по возрасту респонденты были распределены на две группы: 14 человек - до 40 лет, 19 человек - после 40. Профрессиональный стаж работы в модной индустрии - от 5 до 65 лет.

На втором этапе были отобраны материалы для контент-анализа: тексты, видео- и аудиоинтервью с 2018-2021 гг., в которых респонденты выделяли значимые личностные характеристики для профрессиональной самореализации в модной индустрии. В рамках исследования были проанализированы 28 видеоинтервью, 3 аудиоинтервью, 5 документальных фрильмов и 4 онлайн-лекции.

Основным методом исследования стал метод контент-анализа для выявления личностных особенностей дизайнеров. Для статистической обработки данных был использован метод частотного анализа, с помощью которого выявлялась частота упоминаний личностных характеристик, необходимых дизайнеру. В исследовании использовался метод bottom-up, при котором система анализа не задана заранее, а создаётся и дополняется в процессе анализа текста.

Таким образом, материалы были подвергнуты контент-анализу по конструкту «личностные характеристики дизайнеров, необходимые для про- 
Личностные особенности профрессиональной самореализации...

фессиональной самореализации». Полученные данные были проанализированы по частоте встречаемости в изучаемом материале и распределены по трем основным блокам (табл. 1).

Таблица 1

\section{Контент-анализ личностных особенностей дизайнера}

\begin{tabular}{|c|c|c|}
\hline $\begin{array}{c}\text { Категории личностных особенностей } \\
\text { дизайнера }\end{array}$ & $\begin{array}{c}\text { Количество респон- } \\
\text { дентов, отметив- } \\
\text { ших категорию }\end{array}$ & $\begin{array}{c}\text { Частота } \\
\text { упоминаний, \% }\end{array}$ \\
\hline $\begin{array}{l}\text { Чуткость, эмпатия, восприимчивость, } \\
\text { чувствительность к человеку }\end{array}$ & 15 & 45,4 \\
\hline $\begin{array}{l}\text { Коммуникация, умение вести переговоры, } \\
\text { готовность выразить позицию }\end{array}$ & 13 & 39,4 \\
\hline Устойчивость системы ценностей & 11 & 33,3 \\
\hline Свобода самовыражаться, быть собой & 11 & 33,3 \\
\hline Рефлексия & 10 & 30,3 \\
\hline Гибкость & 8 & 24,2 \\
\hline Планирование & 7 & 21,2 \\
\hline $\begin{array}{l}\text { Собранность, сосредоточенность, } \\
\text { сфокусированность }\end{array}$ & 7 & 21,2 \\
\hline Вовлеченность & 7 & 21,2 \\
\hline Стратегическое мышление & 7 & 21,2 \\
\hline $\begin{array}{l}\text { Креативность, желание творить, } \\
\text { потребность в творчестве }\end{array}$ & 6 & 18,2 \\
\hline Целеустремленность & 6 & 18,2 \\
\hline Индивидуальность & 6 & 18,2 \\
\hline Конгруэнтность & 6 & 18,2 \\
\hline Требовательность & 4 & 12,1 \\
\hline Уверенность & 4 & 12,1 \\
\hline Готовность положиться на интуицию & 4 & 12,1 \\
\hline Публичность & 4 & 12,1 \\
\hline Амбициозность & 3 & 9,1 \\
\hline Застенчивость & 2 & 6,1 \\
\hline Оптимистичность & 2 & 6,1 \\
\hline $\begin{array}{l}\text { Быть непохожим, выделяться, быть } \\
\text { заметным }\end{array}$ & 2 & 6,1 \\
\hline Ответственность & 2 & 6,1 \\
\hline Уметь расслабляться & 2 & 6,1 \\
\hline Ирония & 1 & 3,1 \\
\hline
\end{tabular}

Самой распространенной в формулировках и определениях респондентами стала категория чуткость, элпатия, восприилчивость, чувствительность к человеку (45 \%). Вторая по популярности - комлуникация, умение вести переговоръ (39 \%). Наименее употребляемыми стали такие 
Кюрегян А. А.

характеристики, как умение расслабляться, ответственность, оптилистичность, застенчивость (по $2 \%$ ), ирония (3\%).

Первый блок - «Коммуникативная компетентность»

Термин коммуникативная компетентность подразумевает владение сложными коммуникативными навыками и умениями в социальных структурах, знание культурных норм и ограничений в общении, знание обычаев, традиций, этикета в сорере общения, соблюдение приличий, ориентация в коммуникативных средствах в рамках данной профрессии [8]. Мы отнесли к этому блоку две наиболее употребительные категории: коммуникация, умение вести переговоры, готовность выразить позицию (например, «поддерживать взаимодействие с байером», «общаться», "умение вести диалог»), а также чуткость, эмпатия, восприимчивость, чувствительность $к$ человеку как основа восприятия другого человека в коммуникации (например, «понять чувства заказчика», «чувствовать контакт с аудиторией», «создание теплого контакта»). Также сюда вошла и категория публичность (12\%), которая отражает умение дизайнера заявить о своем бренде («позиционировать себя и свою уникальность», «рассказать о продукте более интересным способом»).

Второй блок - «Мотивация и способность к саморегуляции»

Основой саморегуляции поведения и деятельности является мотивационная сорера личности, которая связана с возникновением побуждения к действию и формированием цели [9]. Второй блок включает категорию вовлеченность (21\%) (мотивационное состояние), отмеченную респондентами как необходимость высокой концентрации внимания в деятельности. Саморегуляция понимается нами как единый процесс, способствующий выработке гармоничного поведения, умению управлять собой сообразно реализации поставленной цели, направлять свое поведение в соответствии с требованиями жизни и профессиональными или учебными задачами. [10] Включает в себя категории, относящиеся к регулятивным аспектам личности. Планирование (21 \%) как характеристика сорормированной потребности в осознанном планировании деятельности, умение ставить реалистичные, детализированные, иерархичные задачи. Целеустрелленность (18\%) как возможность выдвижения и удержания целей, которые являются устойчивыми и выдвигаются самостоятельно. Гибкость (24 \%) понимается дизайнерами-экспертами как адаптивность, способность перестраивать собственную деятельность, вносить в нее коррективы («я стараюсь понять голос нового поколения», «нужно идти в ногу со временем»). Категория стратегическое мыиление (21\%) отражает рациональное, стратегическое видение, обозначенное респондентами, например: «идти маленькими, но уверенными шагами», «я могу работать как менеджер», «проактивность». Стратегическое мышление понимается нами как особенный тип системного мышления дизайнера, который объединяет рациональный и творческий компоненты, объективный и субъективный аспекты, основывается на опре- 
Личностные особенности профессиональной самореализации...

деленных принципах, интегрирует разнообразные концепции и методы в сложном процессе его стратегической деятельности [11].

Третий блок - «Рефрлексия»

На высоких позициях в исследовании находится группа категорий, которые отражают значимость понимания дизайнером себя, склонность анализировать собственные переживания, например: «понять себя», «понять свою уникальность», «думай всегда о том, что чувствуешь», «каждый из нас хорошо знает себя». Этот блок включает категории: устойчивость системъ иенностей (33\%), реблексия (30\%), конгруэнтность (18\%), свобода самовыражатъся, бъть собой (11 \%). Дизайнер-профрессионал сегодня охватывает широкий спектр функций - от исследований пользователей до визуального дизайна, - и осознание сильных и слабых сторон необходимо для профессионального роста. Эта необходимость оказывает дополнительное давление, однако понимание себя позволяет в полной мере ощутить личностный потенциал человека в деятельности, позволяет более точно спрогнозировать, за какие проекты браться, помогает специалистам обладать внешней уверенностью и "харизмой», которые так ценятся клиентами и профессиональным сообществом.

Выводы. Личностные особенности являются предметом значительного круга исследований, разветвляющихся на множество самостоятельных научных концепций. Проблемы профессиональной самореализации широко изучаются современными авторами и являются перспективным направлением для исследований. Однако применительно к профессии дизайнера, которая становится для нашей страны все более и более востребованной, эта сорера недостаточно изучена. Нами были проанализированы особенности профессиональной деятельности дизайнера в цифровую эпоху. В результате исследования личностных особенностей профессиональной самореализации были выделены категории, являющиеся необходимыми личностными характеристиками дизайнера, и распределены по трем блокам: «Коммуникативная компетентность», «Мотивация и способность к саморегуляции» и «Рефлексия».

Частое употребление респондентами коммуникативных компетенций отражает субъект-субъект ориентированный характер самой профессии. В особенностях нарратива дизайнеров о профессии выразительно проявляет себя ее предмет - Человек. Это подтверждается и частотой употребления слова «эмпатия» среди важных характеристик личности дизайнера. Данное заключение имеет большой исследовательский потенциал и вызывает интерес, потому как широко распространено мнение о том, что предмет профессии дизайнер - художественный образ. Традиционно относящиеся к описанию качества коммуникации, контакта с другим эти особенности еще раз указывают нам на глубокую специфичность предмета труда дизайнеров. Это не художественный образ сам по себе, не только создание творческого продукта, а глубокое понимание человека. 
Кюрегян А. A.

Полученные данные анализа личностных особенностей профессиональной самореализации дизайнеров позволяют разработать программу эмпирического исследования и продолжить исследовательскую работу, направленную на сравнительный анализ личностных особенностей при разных уровнях профессиональной самореализации. Эти исследования в перспективе дадут основу для создания формирующей программы психологического сопровождения в процессе обучения творческим специальностям и их освоения. В условиях цифрового мира, а также высокой конкуренции в творческой среде видится важным уделять особое внимание личностным характеристикам будущих специалистов, которые помогают достигать высокого уровня профессиональной самореализации.

\section{Ссылки}

1. Креативная индустрия столицы: как развиваются творческие пространства города.URL:https://www.mos.ru/mayor/themes/3299/5563050/?onsite_ molding=1 (дата обращения: 01.02.2021).

2. Zuyeon Kim. The Creativity Crisis: The Decrease in Creative Thinking Scores on the Torrance Tests of Creative Thinking // Creativity Research Journal. October 2011. 23(4). P 285-295.

3. Егорова В. С. Личностные предпосылки готовности студентов-художников к самореализации в социальном контексте творческой деятельности: авторефр. дис. ... канд. психол. наук / Кубанский государственный университет физической культуры, спорта и туризма. Краснодар, 2014. 24 с.

4. Гечи А., Караминас В. Конец моды: одежда и костюм в эпоху глобализации. М.: Новое литературное обозрение, 2020. 288 с.

5. Колышкина Т. Б., Маркова Е. В. Отражение ценностных ориентаций потребителейв рекламнойкоммуникации//Вестник Ярославскогогосударственного университета им. П. Г. Демидова. Серия Гуманитарные науки. 2012. № 4 (22). C. $144-150$.

6. Немирова В. А. Как изменилась потребительская корзина: что хотят покупать сегодня? // Онлайн-форум новой модной индустрии BeinOpen. URL: https://beinopen.ru/mediateka/forum2020_day5\#15 (дата обращения: 10.12.2020).

7. Хитров С. Каким выйдет общество потребления из пандемического кризиса? // Онлайн-фрорум новой модной индустрии BeinOpen. 2020. URL: https://beinopen. ru/mediateka/forum2020_day5\#15 (дата обращения: 02.12.2020).

8. Колмогорова Л. А. Формирование коммуникативной компетентности личности: учебное пособие. Барнаул: АЛТГПУ, 2015. 205 с.

9. Горинов В. В., Корзун Д. Н., Шеховцова Е. С. Мотивационная сфера личности и способность к саморегуляции обвиняемых с расстройствами личности // Психология и право. 2019. Т. 9, № 2. С. 208-221.

10. Моросанова В. И., Коноз Е. М. Стилевая саморегуляция поведения человека // Вопросы психологии. 2000. № 2. С. 118-127.

11. Мещанинов А. А. Дизайн. Точка над і. СПб., 2008. 217 с. 